\title{
Anti-inflammatory and ultrastructural effects of Turkish propolis in a rat model of endotoxin-induced uveitis
}

\author{
Salime Pelin Ertürküner ${ }^{1}$, Elif Yaprak Saraç², Semil Selcen Göçmez ${ }^{3}$, Hakan Ekmekçi, \\ Zeynep Banu Öztürk ${ }^{4}$ İsmail Seçkin ${ }^{1}$, Özkan Sever ${ }^{5}$, Kadircan Keskinbora $^{6}$
}

${ }^{1}$ Istanbul University, Cerrahpasa Faculty of Medicine, Histology and Embryology Department, Fatih/Istanbul, Turkey

${ }^{2}$ Istanbul University, Istanbul Faculty of Medicine, Histology and Embryology Department, Capa,

Fatih/Istanbul, Turkey

${ }^{3}$ Namık Kemal University, Faculty of Medicine, Pharmacology Department, Namık Kemal District, Centrum/Tekirdag, Turkey

${ }^{4}$ Istanbul University, Cerrahpasa Faculty of Medicine, Biochemistry Department, Fatih/Istanbul, Turkey

${ }^{5}$ Namık Kemal University, Faculty of Medicine, Ophthalmology Department, Namık Kemal District, Centrum/Tekirdag, Turkey

${ }^{6}$ Bahcesehir University, Faculty of Medicine, Ophthalmology Department, Sahrayı Cedid District, Yenisahra, Kadıkoy/Istanbul, Turkey

\begin{abstract}
Introduction. Experimental animal models of acute uveitis, an inflammatory eye disease, can be established via endotoxin-induced inflammation. Propolis, a natural substance collected by honeybees from buds and tree exudates, has antioxidant, antibacterial, antiviral, and anti-inflammatory effects. We investigated the effects of propolis, obtained from the Sakarya province of Turkey, on endotoxin-induced uveitis using immunohistochemical, ultrastructural, and biochemical approaches.

Material and methods. Male Wistar albino rats $(\mathrm{n}=6 /$ group $)$ received intraperitoneal $(i p)$ lipopolysaccharide (LPS) endotoxin $(150 \mu \mathrm{g} / \mathrm{kg})$ followed by aqueous extract of propolis $(50 \mathrm{mg} / \mathrm{kg} i p)$ or vehicle; two additional groups received either saline (control) or propolis only. After $24 \mathrm{~h}$, aqueous humor (AH) was collected from both eyes of each animal for analysis of tumor necrosis factor- $\alpha$ (TNF- $\alpha$ ) and hypoxia-inducible factor- $1 \alpha$ (HIF- $1 \alpha)$. Right eyeballs were paraffin-embedded for immunohistochemical staining of nuclear factor $\kappa \mathrm{B}(\mathrm{NF}-\kappa \mathrm{B}) / \mathrm{p} 65$ and left eyeballs were araldite-embedded for ultrastructural analysis.

Results. Treatment of LPS-induced uveitis with propolis significantly reduced ciliary body NF- $\kappa \mathrm{B} / \mathrm{p} 65$ immunoreactivity and AH levels of HIF- $1 \alpha$ and TNF- $\alpha$. Ultrastructural analysis showed fewer vacuoles and reduced mitochondrial degeneration in the retinal pigment epithelium, as compared to the uveitis group. The intercellular spaces of the inner nuclear layer and outer limiting membrane were comparable with those of the control group; no polymorphonuclear cells or stasis was observed in intravascular or extravascular spaces.

Conclusions. This is the first report demonstrating an anti-inflammatory effect of Turkish propolis in a rat model of LPS-induced acute uveitis, suggesting a therapeutic potential of propolis for the treatment of inflammatory ophthalmic diseases. (Folia Histochem Cytobiol. 2016, Vol. 54, No. 1, 49-57)
\end{abstract}

Key words: acute uveitis; propolis; lipopolysaccharide; HIF-1 $\alpha$; TNF- $\alpha$; IHC; electron microscopy; rat

Correspondence address: K. Keskinbora, M.D.

Bahcesehir University, School of Medicine

Ophthalmology Department, Sahrayı Cedid District

Batman Street, No: 66-68, Yenisahra, Kadikoy/Istanbul, Turkey

tel.: +905337358147

e-mail: prpendx@gmail.com 


\section{Introduction}

Endotoxin-induced uveitis (EIU), which serves as an animal model for acute anterior ocular inflammation in humans, can be induced by systemic injection of a sub-lethal dose of lipopolysaccharide (LPS) [1]. The inflammation in EIU is characterized by neutrophil infiltration into the anterior chamber of the eye and up-regulation of cytokine production in the aqueous humor (AH) [2]. The cytokines (tumor necrosis factor- $\alpha$, TNF- $\alpha$, interleukin (IL) $1 \beta$, and IL- 6 ) and chemokines, are considered to be particularly important in the pathogenesis of EIU [3].

Upon stimulation by LPS, nuclear factor $\kappa \mathrm{B}(\mathrm{NF}-\kappa \mathrm{B})$, a primary transcription factor, responds directly, rapidly transducing the external information to DNA via cytoplasmic and nuclear signaling. In the nucleus, $\mathrm{NF}-\kappa \mathrm{B}$ positively regulates the expression of genes involved in inflammatory and immune responses, including TNF- $\alpha[4,5]$. A significant up-regulation of activated NF- $\kappa \mathrm{B}$ in the iris and ciliary body during EIU has been reported [6]. Also, Ilieva et al. demonstrated that LPS induced NF- $\kappa$ B p65 nuclear translocation in the iris and ciliary body [4]. Inhibition of $\mathrm{NF}-\kappa \mathrm{B}$ activation has been shown to have beneficial effects, suppressing acute inflammatory processes [3]. Therefore, the activation of NF- $\kappa \mathrm{B}$ leads to a coordinated increase in the expression of many genes which products mediate the inflammatory loop and perpetuate local inflammatory responses [7].

Hypoxia-inducible factor- $1 \alpha(\mathrm{HIF}-1 \alpha)$, a heterodimeric transcription factor, is a mediator of tissue oxygen homeostasis [8] and interacts with the NF- $\kappa \mathrm{B}$ pathway. These two pathways are regulated by the oxygen status of cells $[9,10]$. The induction of NF- $\kappa \mathrm{B}$ by hypoxia requires the presence of HIF- $1 \alpha$ [11], while HIF- $1 \alpha$ is activated by pro-inflammatory cytokines such as TNF- $\alpha$ and IL- $1 \beta$ in a NF- $\kappa$ B-dependent manner in several normoxic cell lines, including cancer cells [12-14]. Activation of NF- $\kappa$ B leads to TNF- $\alpha$ production, which plays a key role in initiating inflammatory responses, particularly via HIF- $1 \alpha$ activation [11-13].

Propolis is a source of valuable compounds that could contribute to the development of pharmaceuticals or dietary supplements for the prevention or treatment of inflammatory diseases. Ozturk et al. reported that propolis had significant anti-inflammatory effects on EIU in rabbits, comparable to those achieved by corticosteroid treatment [15]. However, the mechanism involved in these anti-inflammatory and protective effects of Turkish propolis against uveitis needs to be characterized. The present study was therefore designed to investigate the anti-inflamma- tory effects of propolis, obtained from the Marmara Sakarya region of Turkey, on EIU.

\section{Material and methods}

Animal study. All experiments were approved by the ethics committee of Cerrahpasa Faculty of Medicine, Istanbul University, Istanbul, Turkey. Animal experiments were conducted in accordance with the NIH Guide for the Care and Use of Laboratory Animals.

Wistar male albino rats were divided into four groups ( $n=6 /$ group): a control group received saline intraperitoneally (ip), a LPS-induced uveitis group received one ip injection of $150 \mu \mathrm{g} / \mathrm{kg}$ LPS (from Salmonella typhimurium; Sigma, St. Louis, MO, USA), a propolis group received $50 \mathrm{mg} / \mathrm{kg}$ Turkish propolis ip [16], and a LPS-induced uveitis group treated with propolis received $150 \mu \mathrm{g} / \mathrm{kg}$ LPS ip followed by $50 \mathrm{mg} / \mathrm{kg}$ Turkish propolis ip. All animals had free access to standard rat chow and drinking water. After $24 \mathrm{~h}$, the rats were anesthetized with ketamine (90 mg/kg, ip) and xylazine $(10 \mathrm{mg} / \mathrm{kg}$, ip $)$ and sacrificed after samples of aqueous humor had been obtained and both eyes had been enucleated.

Immunohistochemistry. The right eyeball of each rat was placed in $10 \%$ neutral formalin for fixation, embedded in paraffin, and cut into $5 \mathrm{~mm}$-thick sections. The sections were mounted on slides coated with poly-L-lysine (Sigma), deparaffinized with toluene (Merck, Darmstadt, Germany), and rehydrated with a graded alcohol series (Merck). Immunoperoxidase staining was performed using the Histostain-Plus Bulk Kit (Zymed, San Francisco, CA, USA) and a rabbit polyclonal NF- $\kappa$ B p65 antibody (sc-109; Santa Cruz Biotechnology, Heidelberg, Germany) using the streptavidin-biotin-peroxidase method [17]. Immunostaining procedures were carried out in accordance with the manufacturer's guidelines. The sections were heated for $15 \mathrm{~min}$ in $10 \mathrm{mM}$ citric acid buffer, pH 6 (DAKO, Glostrup, Denmark) in a microwave oven. The sections were then incubated with $0.3 \% \mathrm{H}_{2} \mathrm{O}_{2}$ in methanol for $10 \mathrm{~min}$ to inactivate endogenous peroxidase activity. The sections were washed with phosphate-buffered saline (PBS) and incubated with normal blocking serum (goat serum). Sections were incubated overnight with NF- $\kappa$ B p 65 antibodies at $4^{\circ} \mathrm{C}$, washed with $\mathrm{PBS}$, incubated with biotinylated secondary antibody (goat anti-mouse), and washed again with PBS. Sections were incubated with a substrate-chromogen solution (AEC; Zymed) for 5-6 min and then incubated with a horseradish peroxidase-streptavidin complex. Sections were counterstained with hematoxylin. To determine the specificity of immunostaining, sections were processed as described above, using control serum in place of the primary antibody. Immunohistochemical staining was evaluated semi-quantitatively using a modified H-SCORE analysis that assigned 
numerical values of $0-300$ to the staining intensity [18]. Each slide was assigned H-SCORE values for 10 different areas by two investigators at different times. The investigators were blinded to the tissue type and source. These scores were averaged to generate the data presented by Karipcin et al. (Figures 1, 2) [18].

Transmission electron microscopy (TEM). The left eyeball of each rat was fixed in $4 \%$ glutaraldehyde (G5882; Sigma) in a $0.1 \mathrm{M}$ phosphate buffer solution, post-fixed in $1 \% \mathrm{OsO}_{4}$ prepared in the same buffer, dehydrated with graded ethanol (Merck), and embedded in araldite (G4901; Sigma). Tissues were cut into ultra-thin 50-nm sections using an ultramicrotome (Reichert UM 2 and UM3, Wien, Austria). The sections were positioned on copper grids (200 mesh), stained with uranyl acetate and lead citrate, and analyzed by TEM (JEM-1011, Jeol, Tokyo, Japan) and an Olympus Soft Imaging camera system (Olympus, Tokyo, Japan). Retinal regions were analyzed and photographed.

Biochemical analyses. At the end of the experiment, $\mathrm{AH}$ samples were obtained from both eyes of each rat by paracentesis. After snap-freezing fresh $\mathrm{AH}$ with liquid nitrogen, AH samples were stored at $-80^{\circ} \mathrm{C}$ until assayed. TNF- $\alpha$ and $\mathrm{HIF}-1 \alpha$ levels in $\mathrm{AH}$ were determined using commercially-available enzyme-linked immunosorbent assays (ELISAs) (rat TNF- $\alpha$ platinum ELISA, cat No. BMS622, eBioscience, Vienna, Austria and rat HIF-1 $\alpha$ ELISA, cat No. E90798Ra USCNK Life Science, Wuhan, China) according to the manufacturers' instructions. The absorbance was measured using a microplate reader at $450 \mathrm{~nm}$. The TNF- $\alpha$ and HIF- $1 \alpha$ concentrations were calculated using a standard curve and expressed as $\mathrm{ng} / \mathrm{mL}$ and $\mathrm{pg} / \mathrm{mL}$, respectively (Figure 3).

Statistical analysis. Semi-quantitative analysis (H-SCORE) of NF- $\kappa \mathrm{B}$ and biochemical analysis of concentration of TNF- $\alpha$ and HIF- $1 \alpha$ levels in all groups were given as mean \pm standard deviation and compared by ANOVA followed by Tukey-Kramer Multiple Comparison Test by GraphPad Instat ver. 3.06 (GraphPad Inc, San Diego, CA, USA). In H-SCORE analysis of NF- $\kappa$ B, statistical significance was defined as $p<0.0001$ for all groups. In biochemical analysis, statistical significance was defined as $p<0.05$ for all groups and $p<0.01$ for propolis and LPS + propolis groups.

\section{Results}

\section{Immunohistochemistry of $\mathrm{NF}-\kappa \mathrm{B} p 65$ in the ciliary body}

Figure 1 shows representative light microscopic images and Figure 2 shows the H-SCORE and statistical analysis of intracellular ciliary body immunohistochemical staining for NF- $\kappa \mathrm{B}$ protein. In LPS-induced uveitis group, both inner and outer ciliary epithelium layers were positively stained, however, connective tissue and ciliary muscles were not characteristically stained. NF- $\kappa \mathrm{B}$ immunoreactivity was significantly stronger in the LPS-induced uveitis group than in the control or propolis groups $(p<0.0001)$. A significant reduction in NF- $\kappa \mathrm{B}$ immunoreactivity was observed in the LPS-induced uveitis group that was treated with propolis $(p<0.0001$; Figure 2$)$.

\section{Biochemical analysis of HIF-1 $\alpha$ and TNF- $\alpha$ in AH} ELISA analyses of HIF- $1 \alpha$ and TNF- $\alpha$ levels in AH (Figure 3) demonstrated that LPS administration significantly increased the levels of these inflammatory markers, as compared with the control group $(p<0.05)$. Propolis treatment significantly reduced the LPS-induced HIF- $1 \alpha$ and TNF- $\alpha$ levels in AH, as compared with the control and propolis groups $(p<0.01$; Figure 3).

\section{Electron microscopy of the neural retina}

TEM analysis of retina's ultrastructure (Figure 4) showed that administration of LPS (Figure 4D-F) resulted in degeneration and swelling of the mitochondria in the retinal pigment epithelium (RPE) (Figure 4E) and expansion of the outer nuclear layer (Figure 4D). Polymorphonuclear cells were also seen in both intravascular and extravascular spaces, especially in the inner plexiform layer and the nerve fiber layer (Figure 4F). Some degeneration and pinocytotic vacuoles were observed in the capillary endothelial cells and there were signs of stasis within capillaries (Figure 4E). In contrast, the LPS-induced uveitis group treated with propolis showed fewer vacuoles and less mitochondrial degeneration in the RPE, as compared with the LPS-induced uveitis group (Figure 4H). The morphology of the intercellular spaces of the inner nuclear layer and the outer limiting membrane were compatible (Figure 4G) with those of the control group (Figure $4 \mathrm{~A}-\mathrm{C}$ ), and there were no signs of stasis in the lumen of capillaries.

\section{Discussion}

EIU is used as an animal model of acute anterior ocular inflammation in humans [1-12]. Systemic injection of LPS caused inflammation of the anterior chamber of the eye, characterized by increased neutrophil infiltration and cytokine levels in the $\mathrm{AH}$ [2]. The inflammatory and immune response involves a transcriptional regulatory factor, NF- $\kappa \mathrm{B}$, which regulates the expression of a number of cytokines [4-12]. However, few studies have investigated NF- $\kappa \mathrm{B}$ expression in the ciliary body during uveitis-related inflammation. Yang et al. reported that NF- $\kappa$ B levels 

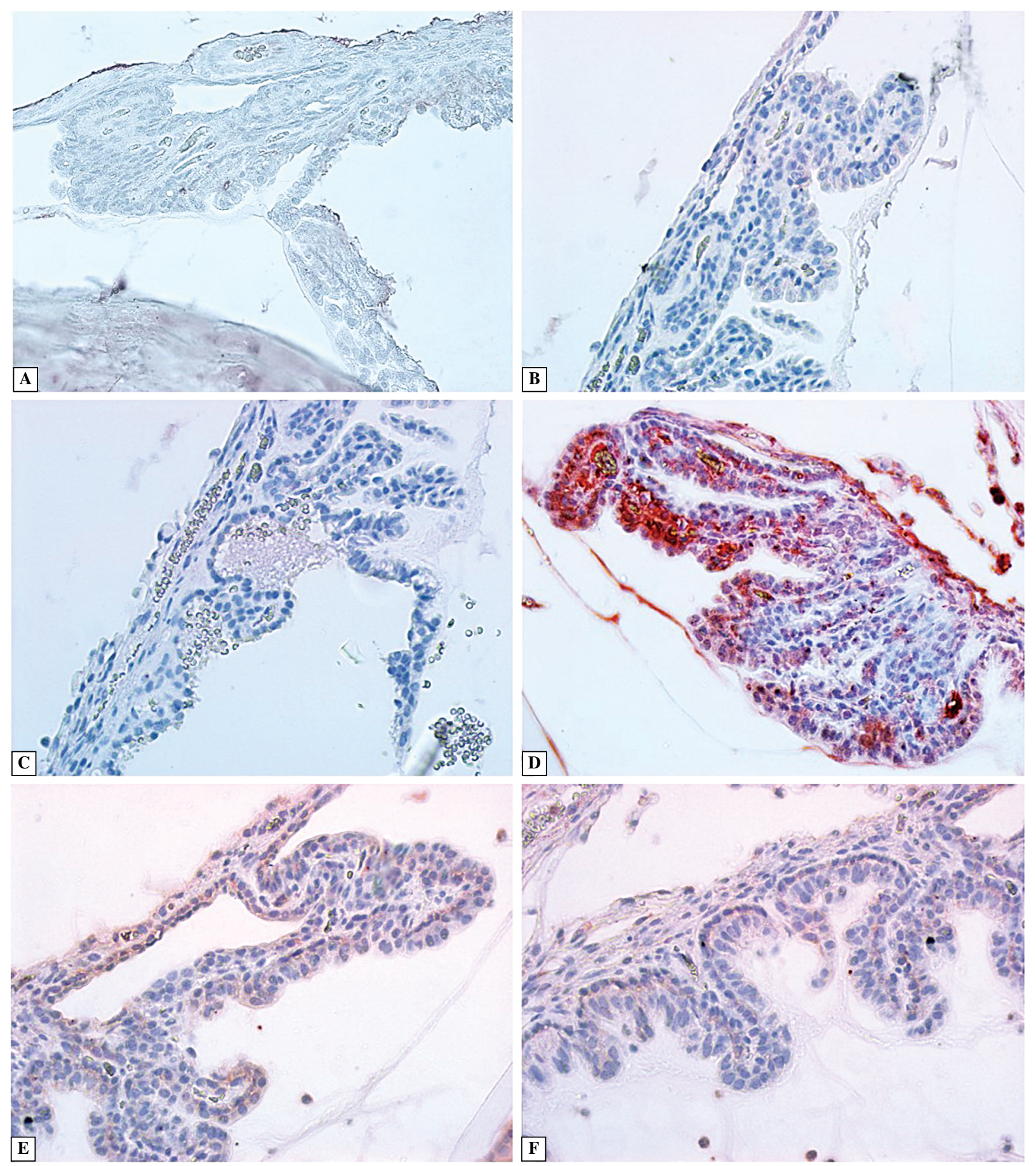

Figure 1A, B. The saline-injected control group: no nuclear factor $\kappa \mathrm{B}(\mathrm{NF}-\kappa \mathrm{B})$ immunoreactivity (Ir); C. The propolis group: no NF- $\kappa$ B Ir; D. Lipopolysaccharide (LPS)-induced uveitis group after 24 h: positive NF- $\kappa$ B Ir; E, F. LPS-induced uveitis group treated with propolis: a significant reduction of the NF- $\kappa$ B Ir. Magnification: $\times 40$

increased significantly following induction of experimental autoimmune anterior uveitis [17]. However, the cytokines controlled by NF-kB activation in uveitis have not yet been defined [14-17]. In the present study, we created a model of EIU that produced acute ocular inflammation in rats. We showed that $24 \mathrm{~h}$ after LPS administration, NF- $\kappa$ B expression was elevated in the ciliary body and TNF- $\alpha$ and HIF- $1 \alpha$ cytokine levels increased in the AH. These findings indicated that TNF- $\alpha$ and HIF 1- $\alpha$ may be involved in the acute inflammation induced by endotoxins (LPS in the current study), and may play a role in the pathogenesis of uveitis. 


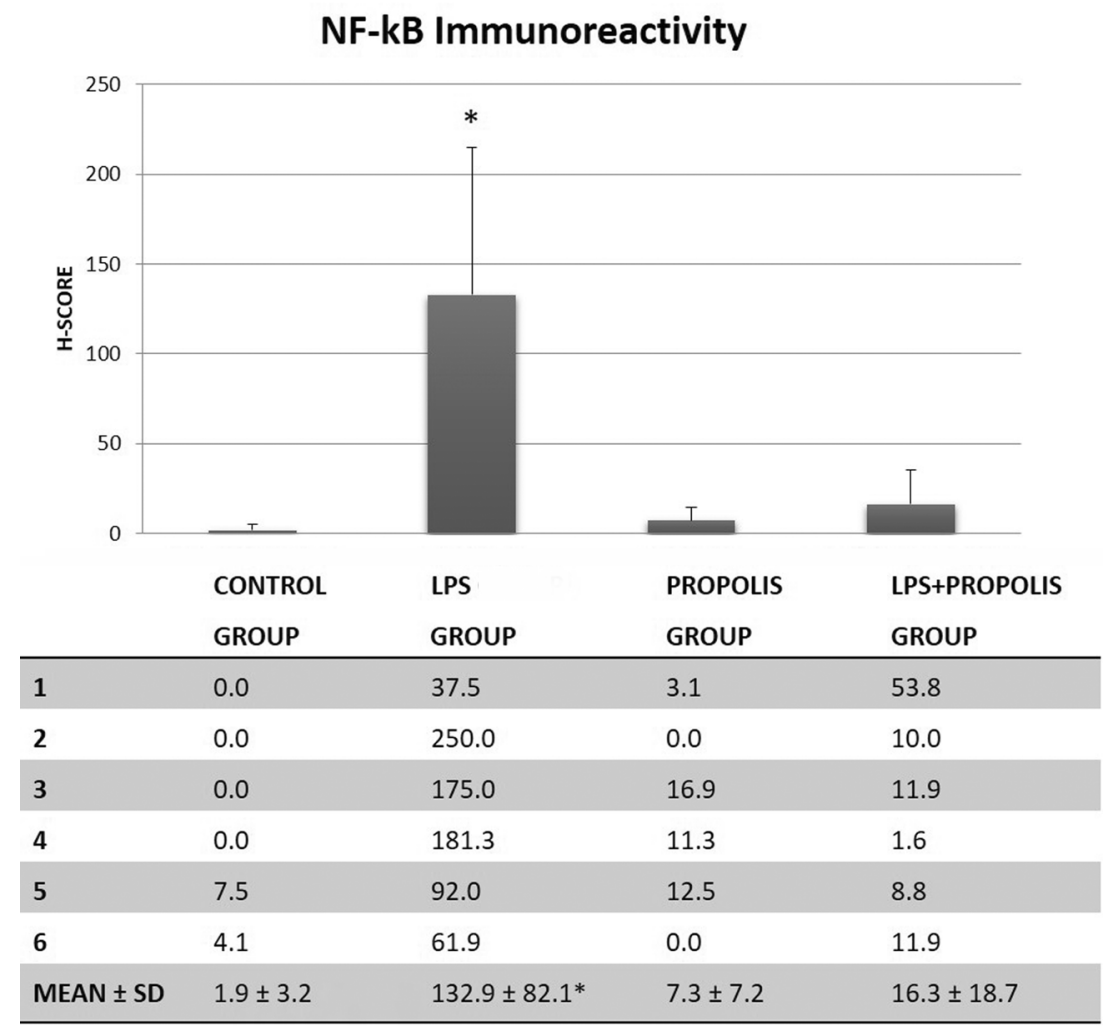

Figure 2. Semi-quantitative (H-SCORE) and statistical analysis of nuclear factor- $\kappa \mathrm{B}$ $(\mathrm{NF}-\kappa \mathrm{B})$ immunoreactivity in the ciliary body of the studied groups of rats. Values are given for each of 6 rats in a group and also as mean \pm standard deviation (SD). LPS - lipopolysaccharide. $* \mathrm{p}<0.0001$, statistically significant differences versus other groups (Tukey-Kramer multiple comparison test)
Propolis has been used for the prevention of inflammatory diseases for centuries. Szilszka et al. showed that artepillin C, which is a compound found in Brazilian green propolis, decreased the LPS-induced inflammatory response and NF- $\kappa \mathrm{B}$ signaling in macrophages [19]. Our findings were also consistent with those of Wang et al., who showed that Chinese propolis extracts decreased the expression of LPS-induced NF- $\kappa$ B by inhibiting phosphorylation of $\mathrm{I} \kappa \mathrm{b}$ and that this reduced TNF- $\alpha$ levels [20]. Girgin et al. showed that the immunomodulatory effects of Turkish propolis on peripheral blood mononuclear cell cultures were dose dependent and involved decreased cytokine release [21]. However, the present study was the first to investigate the anti-inflammatory effects of propolis from Sakarya region of Turkey on experimental acute inflammatory uveitis.

HIF- $1 \alpha$ is known to have various effects on inflammatory processes and its expression level can be altered in a range of diseases [22-24]. The relationship between NF- $\kappa$ B and the HIF-1 pathway may vary depending on the circumstances and cell-type [25, 26]. The results of the present study showed that $\mathrm{NF}-\kappa \mathrm{B}$ was the main inflammatory mediator in this EIU model, and propolis treatment suppressed the levels of NF- $\kappa \mathrm{B}$ in the ciliary body and reduced the levels of proinflammatory cytokines, such as TNF- $\alpha$ and HIF- $1 \alpha$ in the AH. These results suggests that propolis decrease inflammation by reducing NF- $\kappa \mathrm{B}$ level via decreasing TNF- $\alpha$ and HIF- $1 \alpha$ so the anti-inflammatory effect of NF- $\kappa \mathrm{B}$ is mediated by these cytokines.

The retinal ultrastructure in the LPS-induced uveitis group treated with propolis had similarities with that of the control group. The protective and pharmacological effects of propolis on retinal damage have previously been examined in vitro and in vivo $[27,28]$, but these studies did not include electron microscopic examinations. However, Sande et al. identified disorganization of photoreceptor outer segments and significant alterations of cell structure, including expanded intracellular spaces containing dense bodies and membranous debris, $24 \mathrm{~h}$ and 8 days after injection of hamsters with LPS. In addition, a group treated with melatonin, which has immunomodulatory and antioxidant effects, showed a large number of phagosomes in the retina pigment epithelium cells. Our study identified expansion of the outer nuclear layer cells and widening of the intracellular spaces in the LPS-treated group. These effects were less marked in the group treated with both LPS and propolis. This indicated that propolis may stimulate 


\section{HIF-1 $\alpha$}

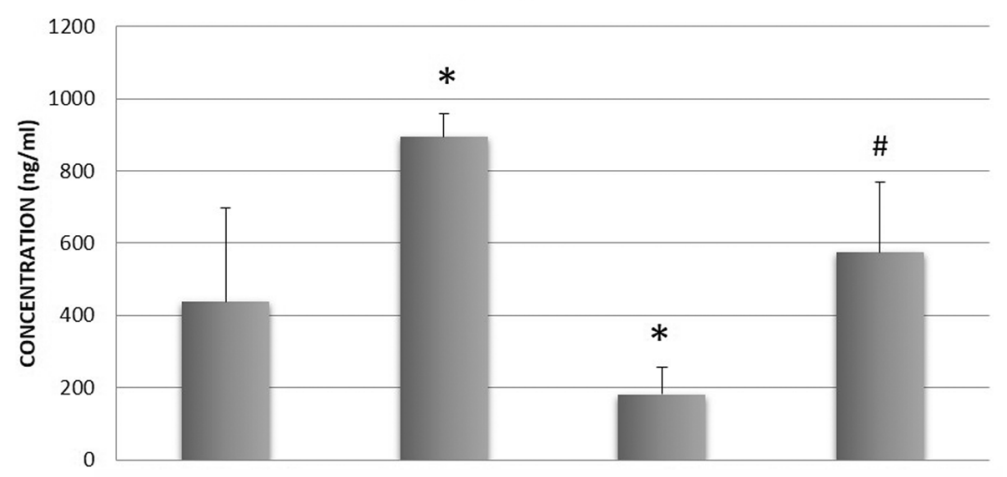

$\mathbf{A}$

\begin{tabular}{|c|c|c|c|c|}
\hline $\mathrm{n}$ & $\begin{array}{l}\text { CONTROL } \\
\text { GROUP }\end{array}$ & $\begin{array}{l}\text { LPS } \\
\text { GROUP }\end{array}$ & $\begin{array}{l}\text { PROPOLIS } \\
\text { GROUP }\end{array}$ & $\begin{array}{l}\text { LPS+PROPOLIS } \\
\text { GROUP }\end{array}$ \\
\hline 1 & 757.99 & 797.36 & 215.32 & 558.55 \\
\hline 2 & 270.97 & 945.44 & 103.19 & 273.52 \\
\hline 3 & 644.15 & 959.14 & 229.87 & 730.60 \\
\hline 4 & 266.68 & 935.17 & 261.54 & 427.59 \\
\hline 5 & 100.62 & 836.74 & 77.51 & 765.69 \\
\hline 6 & 584.23 & 896.65 & 201.62 & 692.94 \\
\hline MEAN \pm SD & $437.44 \pm 259.75$ & $895.08 \pm 65.12^{*}$ & $181.51 \pm 73.81^{*}$ & $574.82 \pm 193.58^{\#}$ \\
\hline
\end{tabular}

TNF- $\alpha$

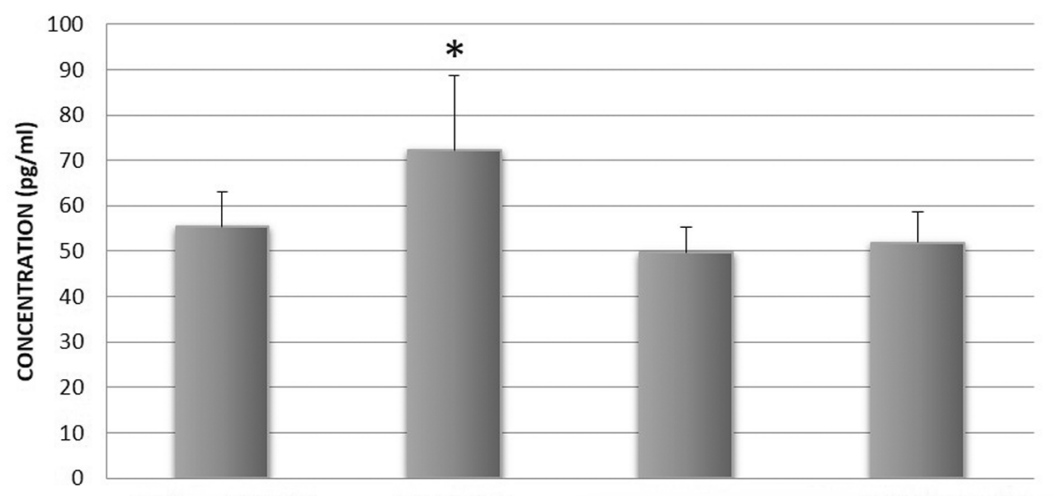

B

\begin{tabular}{|c|c|c|c|c|}
\hline n & $\begin{array}{l}\text { CONTROL } \\
\text { GROUP }\end{array}$ & $\begin{array}{l}\text { LPS } \\
\text { GROUP }\end{array}$ & $\begin{array}{l}\text { PROPOLIS } \\
\text { GROUP }\end{array}$ & $\begin{array}{l}\text { LPS+PROPOLIS } \\
\text { GROUP }\end{array}$ \\
\hline 1 & 49.08 & 58.23 & 45.76 & 54.07 \\
\hline 2 & 58.23 & 57.40 & 43.26 & 44.92 \\
\hline 3 & 44.09 & 69.05 & 55.74 & 45.76 \\
\hline 4 & 64.06 & 74.04 & 54.07 & 47.42 \\
\hline 5 & 54.07 & 72.38 & 54.07 & 60.73 \\
\hline 6 & 62.39 & 102.33 & 44.92 & 58.23 \\
\hline $\mathrm{MEAN} \pm \mathrm{SD}$ & $55.32 \pm 7.76$ & $72.24 \pm 16.34 *$ & $49.64 \pm 5.56$ & $51.86 \pm 6.77$ \\
\hline
\end{tabular}

Figure 3. Concentrations of hypoxia-inducible factor- $1 \alpha(\mathrm{HIF}-1 \alpha)$ (A) and tumor necrosis factor- $\alpha$ (TNF- $\alpha)$ (B) in the aqueous humor of the studied groups of rats. Values are given for each of 6 rats in a group and also as mean \pm standard deviation (SD), data are expressed in $\mathrm{ng} / \mathrm{mL}$. ${ }^{*} \mathrm{p}<0.05$, statistically significant differences versus control group; ${ }^{\#} \mathrm{p}<0.01$, statistically significant difference between Propolis group and lipopolisaccharide (LPS) + Propolis group (Tukey-Kramer multiple comparison test) 

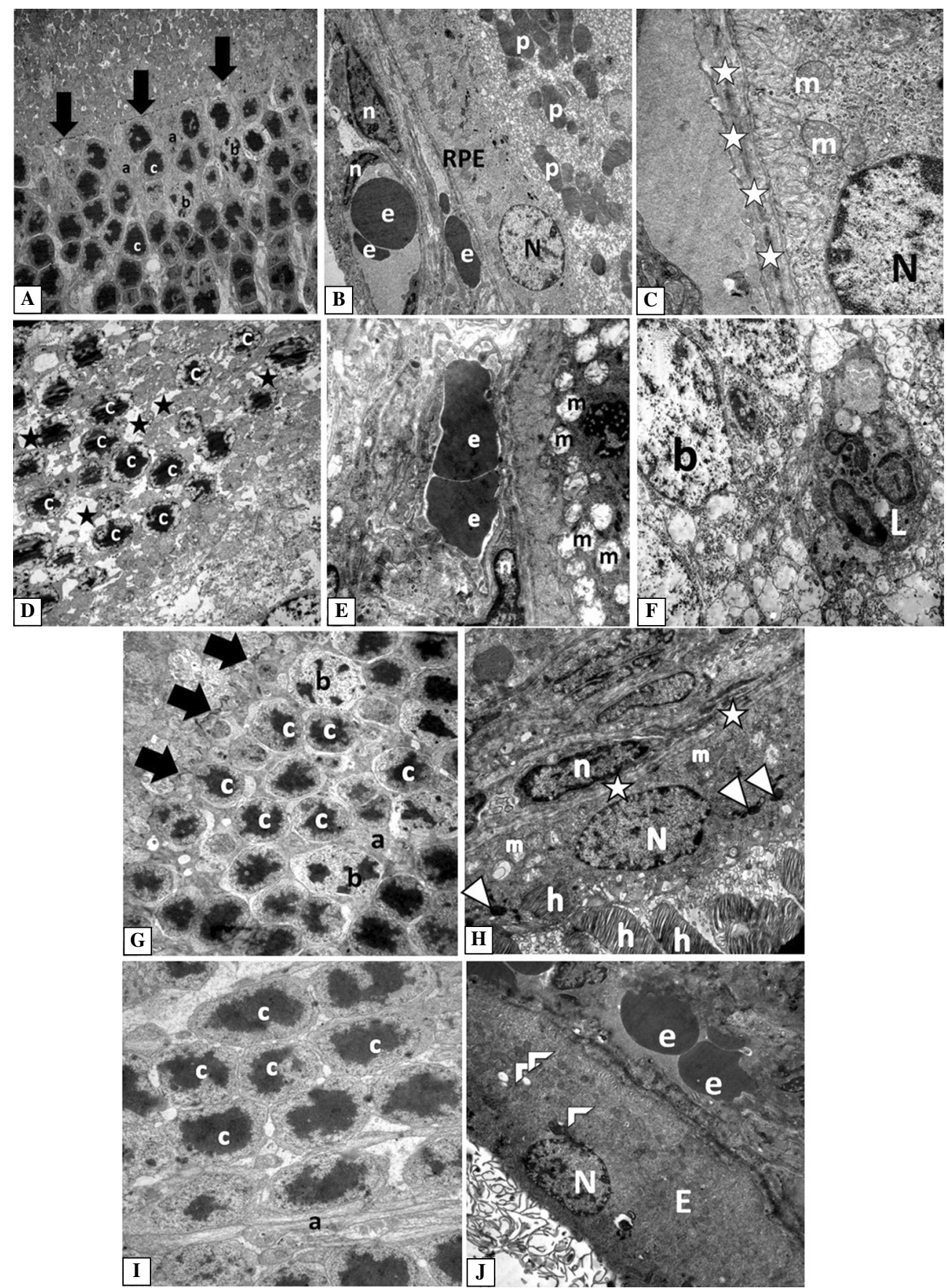

Figure 4. Ultrastructure of the retina of the studied groups of rats. Control group (A-C): A. Outer nuclear layer, outer limiting membrane, rod and cone layer and (B) retinal pigment epithelium in relation to (C) choroid and photoreceptor layer of the retina. Symbols: (a) normal outer rod fibers, (b) cone and (c) rod nuclei, (arrow) outer limiting membrane, (RPE) retinal pigment epithelium and $(\mathrm{N})$ nuclei, $(\mathrm{m})$ mitochondria, (n) capillary endothelial nucleus, (e) erythrocytes, (p) outer segment of photoreceptor, (white star) Bruch's membrane can be observed. Magnifications: A: $\times 3,000 ;$ B: $\times 6,000$; C: $\times 25,000$. Lipopolysaccharide (LPS)-treated rats (uveitis group, D-F): D. Shows the inner nuclear layer, (E) RPE in relation to choroid, and (F) the inner plexiform layer. Symbols: (black stars) dilated spaces between degenerated rod cells, (m) degenerated mitochondria, (L) polymorphonuclear cell. Other symbols as in the description of Figures 4A-C. Magnifications: D: $\times 5,000 ; \mathrm{E}: \times 15,000 ; \mathrm{F}: \times 6,000$. LPS + propolis group $(\mathbf{G}, \mathbf{H})$ : G. Shows the outer nuclear layer; H. Shows RPE in relation to the choroid layer. Symbols: (arrow) outer limiting membrane, (a) outer rod fiber, (N) RPE nuclei with (white triangle) their pigment granules, and (h) outer segment of photoreceptor and $(\mathrm{m})$ normal mitochondria can be observed. Magnifications: G: $\times 5,000 ; \mathrm{H}: \times 12,000$. The propolis group (I, J): I. Shows an outer nuclear layer; J. Shows RPE in relation to the choroid layer. Symbols: (a) normal outer rod fibers, (c) rod nucleus, $(N)$ nucleus of RPE, (half white frame) mitochondria and (e) erythrocyte can be observed. Magnifications: I: $\times 7,500 ; \mathrm{J}: \times 6,000$ 
repair of the outer nuclear layer of the neural retina; this hypothesis will be tested in a future study of propolis in chronic uveitis [29].

In conclusion, the therapeutic effects of propolis observed in this study and others indicate that various types of propolis can act as anti-inflammatory agents and protect from conditions such as uveitis. Propolis obtained from Turkey may provide a promising anti-inflammatory agent for the treatment of ophthalmic diseases such as uveitis.

\section{Acknowledgements}

This study was supported by The Scientific Research Projects Coordination Unit of Namik Kemal University (Project no: NKUBAP.00.20.AR.12.01) and was conducted in the Histology and Embryology Department of Cerrahpasa Medical School, Istanbul University, Turkey. We would like to acknowledge the support of Azize Gumusyazici and Ercument Boztas, in the electron microscopy laboratory, Cerrahpasa Medical School, Istanbul University. We also appreciate Aksu Vital Chemical Company for providing us the propolis extract.

\section{Competing interests}

The authors declare that they have no competing interests.

\section{Author contribution}

The research concept and design were developed by Salime Pelin Ertürküner. Animal experiments were carried out by Salime Pelin Ertürküner, Elif Yaprak Saraç, Semil Selcen Göçmez, Özkan Sever, and Kadircan Keskinbora. Immunohistochemical studies were conducted by Salime Pelin Ertürküner and Elif Yaprak Saraç. Hakan Ekmekçi and Zeynep Banu Öztürk carried out the biochemical studies. Transmission electron microscope studies were conducted by Salime Pelin Ertürküner, supervised by İsmail Seçkin.

\section{References}

1. Rosenbaum JT, McDevitt HO, Guss RB, Egbert PR. Endotoxin-induced uveitis in rats as a model for human disease. Nature. 1980;286:611-613. PMID: 7402339.

2. Shiratori K, Ohgami K, Ilieva IB, Koyama Y, Yoshida K, Ohno $\mathrm{S}$. Inhibition of endotoxin-induced uveitis and potentiation of cyclooxygenase-2 protein expression by alpha-melanocyte-stimulating hormone. Invest Ophthalmol Vis Sci. 2004;45:159-164. doi: 10.1167/iovs.03-0492.

3. Chen F, Castranova V, Shi X. New insights into the role of nuclear factor-kappa B, a ubiquitous transcription factor in the initiation of diseases. Clin Chem. 1999;45:7-17. PMID: 9895331.
4. Ilieva I, Ohgami K, Jin XH et al. Captopril suppresses inflammation in endotoxin-induced uveitis in rats. Exp Eye Res. 2006;83:651-657. doi: 10.1016/j.exer.2006.03.005.

5. Jin XH, Ohgami K, Shiratori K et al. Effects of blue honeysuckle (Lonicera caerulea L.) extract on lipopolysaccharide-induced inflammation in vitro and in vivo. Exp Eye Res. 2006;82:860-867. doi: 10.1016/j.exer.2005.10.024.

6. Vallabhapurapu S, Karin M. Regulation and function of NF-kappaB transcription factors in the immune system. Annu Rev Immunol. 2009;27:693-733. doi: 10.1146/annurev. immunol.021908.132641.

7. Baker RG, Hayden MS, Ghosh S. NF-kB, inflammation, and metabolic disease. Cell Metab. 2011;5:11-22. doi: 10.1016/j. cmet.2010.12.008.

8. Hotamisligil GS, Erbay E. Nutrient sensing and inflammation in metabolic diseases. Nat Rev Immunol. 2008;8:923-934. doi: $10.1038 /$ nri2449.

9. Siegert I, Schödel J, Nairz M et al. Ferritin-Mediated Iron Sequestration Stabilizes Hypoxia-Inducible Factor- $1 \alpha$ upon LPS Activation in the Presence of Ample Oxygen. Cell Rep. 2015;13:2048-2055. doi: 10.1016/j.celrep.2015.11.005.

10. Solinas G, Karin M. JNK1 and IKKb: molecular links between obesity and metabolic dysfunction. FASEB J. 2010;24:2596-2611. doi: 10.1096/fj.09-151340.

11. Jin $\mathrm{XH}$, Ohgami K, Shiratori $\mathrm{K}$ et al. Inhibitory effects of lutein on endotoxin-induced uveitis in Lewis rats. Invest Ophthalmol Vis Sci. 2006;47:2562-2568. doi: 10.1167/iovs.05-1429.

12. Zheng $\mathrm{C}$, Lei $\mathrm{C}$, Chen $\mathrm{Z}$ et al. Topical administration of diminazene aceturate decreases inflammation in endotoxin-induced uveitis. Mol Vis. 2015;10:403-411. PMID: 25883526.

13. Haddad JJ, Harb HL. Cytokines and the regulation of hypoxia-inducible factor(HIF)-1alpha. Int Immunopharmacol. 2005;5:461-483. Erratum in: 2006;6:1632. doi: 10.1016/S00145793(01)02833-2.

14. Kitamei H, Iwabuchi K, Namba K et al. Amelioration of experimental autoimmune uveoretinitis (EAU) with an inhibitor of nuclear factor-kappaB (NF- $\kappa \mathrm{B})$, pyrrolidine dithiocarbamate. J Leukoc Biol. 2006;79:1193-1201. doi: 10.1189/jlb.0805453.

15. Ozturk F, Inan UU, Emiroglu M, Ilker SS, Sobaci G. Effect of propolis on endotoxin-induced uveitis in rabbits. Jpn J Ophthalmol. 1999;43:285-289. PMID: 10482473.

16. Orsolić N, Basić I. Antitumor, hematostimulative and radioprotective action of water-soluble derivative of propolis (WSDP). Biomed Pharmacother. 2005;59:561-570. doi: 10.1016/j.biopha.2005.03.013.

17. Yang CH, Fang IM, Lin CP, Yang CM, Chen MS. Effects of the NF- $\kappa$ B inhibitor pyrrolidine dithiocarbamate on experimentally induced autoimmune anterior uveitis. Invest Ophthalmol Vis Sci. 2005;46:1339-1347. doi: 10.1167/iovs.04-0640.

18. Karipcin FS, Ensari TA, Kayisli UA, Guzel E, Kallen CB, Seli E. The mRNA-binding protein HuR is regulated in the menstrual cycle and repressed in ectopic endometrium. Reprod Sci. 2011;18:145-155. doi: 10.1177/1933719110382307.

19. Szliszka E, Mertas A, Czuba ZP, Król W. Inhibition of inflammatory response by artepillin C in activated RAW264.7 macrophages. Evid Based Complement Alternat Med. 2013;2013:735176. doi: 10.1155/2013/735176.

20. Wang K, Ping S, Huang S et al. Molecular mechanisms underlying the in vitro anti-inflammatory effects of flavonoidrichethanol extract from Chinese propolis. Evid Based Complement Alternat Med. 2013;2013:127672. doi: 10.1155/2013/127672.

21. Girgin G, Baydar T, Ledochowski M et al. Immunomodulatory effects of Turkish propolis: changes in neopterin release and tryptophan degradation. Immunobiology. 2009;214:129-134. doi: 10.1016/j.imbio.2008.07.002. 
22. Sethi G, Shanmugam MK, Ramachandran L, Kumar AP, Tergaonkar V. Multifaceted link between cancer and inflammation. Biosci Rep. 2012;32:1-15. doi: 10.1042/BSR20100136.

23. Kong T, Eltzschig HK, Karhausen J, Colgan SP, Shelley CS. Leukocyte adhesion during hypoxia is mediated by HIF1-dependent induction of $\beta 2$ integrin gene expression. Proc Natl Acad Sci USA. 2004;101:10440-10445. doi: 10.1073/ /pnas.0401339101.

24. Karhausen J, Furuta GT, Tomaszewski JE, Johnson RS, Colgan SP, Haase VH. Epithelial hypoxia-inducible factor-1 is protective in murine experimental colitis. J Clin Invest. 2004;114:1098-1106. doi: 10.1172/JCI200421086.

25. Walmsley SR, Print C, Farahi N et al. Hypoxia-induced neutrophil survival is mediated by HIF-1a-dependent NF- $\kappa$ B activity.JExp Med. 2005;201:105-115. doi: 10.1084/jem.20040624.

26. Yorulmaz H, Ozkok E, Erguven M, Ates G, Aydin I, Tamer S. Effect of simvastatin on mitochondrial enzyme activities, ghrelin, hypoxia-inducible factor $1 \alpha$ in hepatic tissue during early phase of sepsis. Int J Clin Exp Med. 2015;15:3640-3650. PMID: 26064259.

27. Inokuchi Y, Shimazawa M, Nakajima Y, Suemori S, Mishima $\mathrm{S}$, Hara $\mathrm{H}$. Brazilian green propolis protects against retinal damage in vitro and in vivo. Evid Based Complement Alternat Med. 2006;3:71-77. doi: 10.1093/ecam/nek005.

28. Murase H, Shimazawa M, Kakino M, Ichihara K, Tsuruma K, Hara $\mathrm{H}$. The effects of Brazilian green propolis against excessive light-induced cell damage in retina and fibroblast cells. Evid Based Complement Alternat Med. 2013;2013:238279. doi: $10.1155 / 2013 / 238279$.

29. Sande PH, Fernandez DC, Aldana Marcos HJ et al. Therapeutic effect of melatonin in experimental uveitis. AmJ Pathol. 2008;173:176. doi: 10.2353/ajpath.2008.080518.

Submitted: 2 October, 2015 Accepted after reviews: 23 March, 2016 Available as AoP: 5 April, 2016 